\title{
Big Data Analytics of the Representation of Physical Education in Social Media
}

\author{
Caly Setiawan ${ }^{1, *}$ Muhammad Hamid Anwar ${ }^{1,}$ Fathan Nurcahyo ${ }^{1}$ \\ ${ }^{1}$ Department of Physical Education, Yogyakarta State University, Yogyakarta, Indonesia \\ *Corresponding author.Email: csetiawan@uny.ac.id
}

\begin{abstract}
The purpose of the current study was to understand the representation of physical education (PE) in social media. We used big data analytics to access the data of the representation and to map out the large scale of representation in four major social media platforms. The data were collected by extracting social media posts from January to December 2020. This involved big data analytics by which information has been ranked, categorized, and classified through its machine learning. Data analysis included computational analytics producing data visualization. Results showed three overarching the themes of the representation of PE along with its contributors in social media.
\end{abstract}

Keywords: Representation, Physical Education, Social Media, Big Data Analytics

\section{INTRODUCTION}

Protective measures for COVID-19 to socially and physically distance has, in fact, accelerated the transformation of social media into becoming a major part of social reality. This transformation also leaves digital traces not only at a rapid speed but also in massive amounts of data and a diverse spectrum of contents. One way or another, these traces reflect how today's society is organized and how reality is socially constructed.

Educational scholars have long considered that school subjects such as physical education (PE) are social constructions [1]. It means that the understanding and meanings of those subjects are socially created, built, discovered, and negotiated the understanding and meaning by the members of society. In PE, one emerging process of social construction is through the electronically mediated representation of the school subject in social media, online newspapers, films, and other presentations of popular culture. It has been learned from the classic theory of representation that people use language or symbolic systems to communicate the meaning of PE or to represent it toward others [2]. As the re/production of meaning, representation can refer to factual or imaginary objects, human beings, or events. Regardless of the nature of its reality, PE representation entails particular interests and agendas from those who communicate it.

Literature has continually documented information on the representation of PE in media. For example, media tended to maintain discourse about PE around healthism with notorious highlights on physicality such as activity, health, obesity, physical activity, and exercise [3].
Another type of media such as movies represented images of PE as an arena for bullying and constructing masculinism [4]. Similarly, representation of PE in movies also constructed images of PE teachers as butches, bullies, and buffoons [5].

Furthermore, PE researchers have already begun to focus on social media, especially on the aspect of the use of social media. For example, teachers used Twitter to develop a sense of belonging within their community of practice, reducing the perception of being isolated, helping these teachers with taking initiatives, and supporting their professional development [6, 7, 8]. Social media contents have also been investigated as PE learning sources which included physical literacy [9] and health-related information [10]. Little attention has, however, been given to the social media research aimed at understanding social phenomena. Few exceptions included some studies investigating PE practices represented on YouTube in 27 different countries [11] and teachers's ways to develop their day-to-day philosophy with regard to physical literacy through conversations on Twitter [12].

Equally important, further social media research on PE may take advantage of big data. As a newly emerging field, big data analytics allows researchers to benefit from the handles, extractions, and analyses of gigantic datasets that have been digitally left behind by social media users. Big data analytics include algorithm processes such as sentiment analysis, machine learning, and data visualization. This decoded information is characterized by huge volume, high velocity, and diverse variety making big data different from other datasets management and processes [13]. This qualitative study 
aimed at understanding the representation of PE in social media through big data analytics. A research question was developed to guide the study, including: what are the top representational topics of PE in social media, and who have contributed to those topics?

\section{METHOD}

\subsection{Context}

The context of the current study was virtual locations in which we studied human action in social media. However, the language of the social media posts as a result of query words in Bahasa Indonesia located online activities taking place in this country. In other words, this reflected $\mathrm{PE}$ in Indonesia. In addition, the time frame of the study was from January to December 2020. Most of the school days during the year were dominated by distance learning due to the COVID-19 pandemic. Although the extracted posts did not always reflect what had happened during this time period, the condition of the pandemic became an important context in which the social media users engaged in online activities.

\subsection{Data Collection}

We began data collection with big data analytics by determining a set of query words in Bahasa Indonesia. The English translation included "physical education", "health" and "physical education", "PE", and "HPE". The set was also made of ordinary terms commonly associated with the subject such as "physed", "gym class", "sports learning", and "physed/sports teachers". Since the query words were in Bahasa Indonesia, the results of all extracted contents were also in the same language. Additionally, our query words also limited the location of the content posted to mostly being from Indonesia. Our initial query has extracted 19.171 posts from the four major social media platforms.

\subsection{Data Analysis}

The data analysis took advantage of the machinery analysis performed by big data analytics. This included machine learning algorithms to extract the social media data and process the data through indexing and issue ranking. We carefully selected data that were produced from this simple processing such as the number of posts and engagement activities, location detections, and issue ranking. In other words, we did not take into consideration the complex analysis involving semantic processing, natural language detection, and relationship detection in which the validity and reliability have still been undetermined. Furthermore, the extraction data was broken down into visualization entities such as demographic information, activities, users' locations, topics, and engagements and then described narratively.

\section{RESULTS AND DISCUSSION}

\subsection{Results}

The big data analytics produced data informing topics of physical PE from 19.171 posts. The machine learning algorithm also ranked these topics based on the identification of the most discussed issues. Figure 1 displays the top topics regarding PE. Among these topics, the top three included PE teachers (47.6\%), PE learning $(16.6 \%)$, and students $(8.2 \%)$. Other issues were shared in almost equal values (approximately 7\%). It is noteworthy that these were the top topics and there might be other topics that were not displayed by the big data analytics because of their insignificant counts.

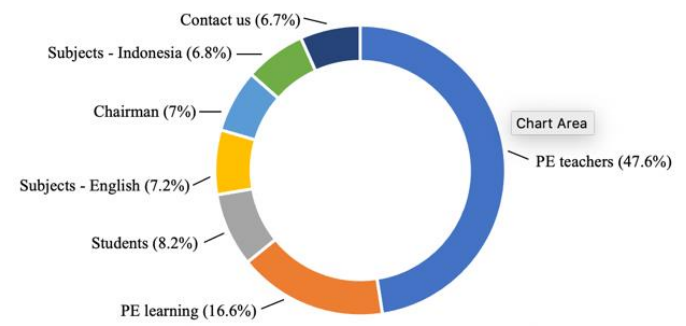

Figure 1 Top representational topics regarding physical education in social media.

Who were the contributors and how they contributed to these representational topics? The big data analytics extracted posts being contributed by 14.324 social media accounts. Some of these have been identified their gender with male contributors were slightly more than the females. Almost a half of them were married. They were also relatively young with more contributors being below 30 years old. Slightly more than half of the contributors had high school diplomas and the remaining half of them had higher education degrees, particularly some college diplomas. Table 1 describes the demographic data of some contributors to the topic of PE.

Table 1. Demographic data of some of the contributors.

\begin{tabular}{|l|c|c|}
\hline & $N$ & Percent \\
\hline Gender & & \\
\hline Male & 5.496 & 57,9 \\
\hline Female & 3.992 & 42,1 \\
\hline Martial Status & & \\
\hline Married & & \\
\hline Not currently married & 4.492 & 47,4 \\
\hline & 4.984 & 52,6 \\
\hline Age & & \\
\hline$<18$ & & \\
\hline $18-21$ & 2.887 & 30,2 \\
\hline $22-30$ & 785 & 8,2 \\
\hline $31-40$ & 3.369 & 35,2 \\
\hline $41-55$ & 1.701 & 17,8 \\
\hline$>55$ & 562 & 5,9 \\
\hline & 257 & 2,7 \\
\hline Last education & & \\
\hline Hight school & 4.287 & 52,3 \\
\hline College & 3.493 & 42,6 \\
\hline Graduate school & 411 & 5,1 \\
\hline
\end{tabular}


One typical way that the contributors engaged with the topics was through posting textual microblogs (e.g., posts, replies, tweets, retweets, status updates). The other ways included photo, video, and link sharing which made up $38,2 \%$ of the total post composition.

The big data analytics also extracted the post exposure (see Figure 2). More specifically, Twitter and Facebook had the tendency of more PE-related content being posted between March and April or the first months of the COVID-19 pandemic. PE had become an increasing topic again during the months of June and July when the academic year began for the first time with distance learning methods. However, the social media users of these two platforms seemed to lessen their engagement with PE content at the end of the semester. In the case of Instagram and YouTube, their post exposure tended to increase in the first months of the pandemic (April) and academic year (August). This was the time when PE learning might take advantage of the availability of visual and audiovisual contents to help with learning movement or skill development. During the months of November to December, the topics about PE became more exposed which might indicate the increased numbers of users engaging in posts related to the end of semester routines (e.g., final assignments, tests, assessments).

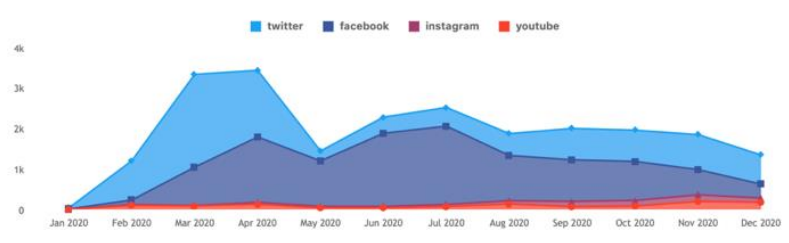

Figure 2 Post exposure of physical education topics in four major social media platforms (image retrieved from Intelligence Socio Analytics, reprinted with permission from Ebdesk)

The contributors engaged with the issues through numbers of likes (1.226.204), comments and replies (29.403), and shares (59.520). We were also interested in looking at the specific social media users engaging in these posts. With the exception of YouTube (e.g., 18+ years old), the social media in this study restrict users only for those aged 13 and over. Facebook was populated by users aged between 18 to 30 years old. They might be, at least, high school graduates currently in college or in their early careers. If not single, they were possibly newly married users with relatively young children. Accounts with school-aged users (e.g., <18 years old) were less than $1 \%$, indicating that Facebook exposure related to physical education during the early months of the pandemic and academic year did not involve significant numbers of students. In contrast, school-aged accounts were much higher on Twitter (28.8\%) suggesting that some students might respond to the topics relatively the same way as the other Facebook users. The under-18 users were even more on Instagram (35.6\%) illustrating that their engagement with the topics was likely to happen during the school days and increase at the end of the semester.

\subsection{Discussion}

Through big data analytics, the current study revealed representational topics within which PE teachers, PE learning, and students ranked the top three most discussed topics. It indicates the centrality of this triangle interaction (teacher-students-the event of learning) within the discourse of PE. Big data is also powerful in extracting information about the contributors of $\mathrm{PE}$ representation in social media. Interestingly, males and females have almost equally contributed to the representation although the literature has documented the dominance of masculinity in PE $[14,15,16]$. It can be inferred that social media may potentially become an important outlet to express aspiration and voice for those who have so far been curbed in PE.

If representation communicates meaning [2], furthermore, what does it convey the meaning of PE though social media? Our efforts to thicken the data from big data analytics and then to further analyze those interpretatively have allowed us to look deeper into the meanings of PE. It is obvious that a high variety of meanings exist as a result of different PE experiences among social media users. However, analysis has enabled us to identify meaningful tones within their posts and engagements. These tones include the less intellectual nature of the subject matter and the emphasis on physicality. Research findings informing these meaningful tones may not be a new addition to our understandings of the literature. Abundant works dedicated to examining these related issues $[17,18]$ have crystalized conclusive knowledge on the meaning of PE. Specific studies on the representation of PE [3] also implicitly inform similar understandings. But the current study took an alternative pathway to contribute to the literature by considering data in which the information was not the social media users' responses to our questions. These users might genuinely express their thoughts, feelings, and attitudes toward PE so that trustworthy analytical processes can be promising in revealing more authentic meanings.

Like major aspects in education, COVID-19 has created serious disruptions in PE. Research within this area of literature is still emerging and far from being conclusive. However, a number of studies have begun to inform how $\mathrm{PE}$ has changed as a result of the implementation of distant learning. A study showed that pre-service PE teachers experience a disruption in their teaching practicum as PE assemblage has changed from body constituted to less tactile approaches [19]. Another study revealed that $\mathrm{PE}$ teacher education programs across Europe sought to resolve the tension between the experiential nature of $\mathrm{PE}$ and the blended approach to learning [20]. The current study adds to such similar knowledge on which PE has disruptively been experienced by teachers, parents, and students. It showed how the experiential nature of PE had to be electronically mediated. The pandemic left teachers with pedagogical anxiety as teaching became touchless and students' bodies were absent [19]. However, social media users expressed that parents have extended teachers' roles to tactilely deliver PE. 


\section{CONCLuSion}

Exploring the meaning of PE will be advanced from taking social media research into consideration. Borrowing the classic social constructionist framework [21], this study can be an important part of inquiries into the meaning of PE in which the members of a society conjointly construct what PE means to them and what assumes to be the reality of PE. Through social media platforms, people apparently co-constructed PE that was centralized around the topics about PE teachers, PE learning, and students. Further analysis also showed typical tones within the representation of PE such as physicality and masculinity. The current pandemic has also become a global context served as a backdrop in which PE has locally been implementing. One way or another, activities and engagement in social media platforms reflected this condition.

Technically speaking, the overall presentation of the results has been enabled by big data analytics. Surely, we deal with such a large dataset at the outset. Analytical features within big data processes have enabled data extraction and presentation informing the central topics, users' profiles, their locations, and times of engaging with social media. We would not be able to work with such enormous data in traditional ways of data processing if we might not have utilized big data analytics. When this became the channel for a qualitative inquiry, it can promise alternative perspectives toward what we have understood all this time, or even new knowledge and understanding in educational literature.

\section{REFERENCES}

[1] Kirk D. (1992). Defining physical education: The social construction of a school subject in postwar Britain. London: Routledge Falmer.

[2] Hall S. (1997). The work of representation. In S. Hall (ed), Representation: Cultural representations and signifying practices (pp. 13-74). London: SAGE Publication Ltd.

[3] Hyndman B. P., Harvey S. (2020). Preservice teachers' perceptions of Twitter for health and physical education teacher education: A selfdetermination theoretical approach. Journal of Teaching in Physical Education 39, 472-480. DOI: https://doi.org/10.1123/jtpe.2019-0278

[4] Walton-Fisette J. L., Walton-Fisette T. A., Chase L. F. (2017). Captured on film: A critical examination of representations of physical education at the movies. Physical Education and Sport Pedagogy 22,
http://dx.doi.org/10.1080/17408989.2017.1294670

[5] McCullick B., Belcher D., Hardin B., Hardin, M. (2003). Butches, bullies and buffoons: images of physical education teachers in the movies. Sport, Education, \& Society 8, 3-16. DOI: http://dx.doi.org/10.1080/1357332032000050033

[6] Brook C., McMullen, J. M. (2020). Using social media: One physical education teacher's experience. Journal of Teaching in Physical Education 39, 464471. DOI: https://doi.org/10.1123/jtpe.2020-0005

[7] Goodyear V. A., Casey A., Kirk, D. (2014). Tweet me, message me, like me: using social media to facilitate pedagogical change within an emerging community of practice. Sport, Education \& Society 19, 927-943. DOI: http://dx.doi.org/10.1080/13573322.2013.858624

[8] Richard K A., Killian C. M., Kinder C. J., Badshah K., Cushing C. (2020). Twitter as a professional development platform among U.S. physical education teachers. Journal of Teaching in Physical Education 39, 454-463. DOI: https://doi.org/10.1123/jtpe.2020-0001

[9] Bopp T., Vadeboncoeur J. D., Stellefson M, Weinz M. (2019). Moving beyond the gym: A content analysis of YouTube as an information resource for physical literacy. Int. J. Environ. Res. Public Health 16 , $1-18$.

DOI: https://doi.org/10.3390/ijerph16183335

[10] Goodyear V., Armour K. M., Wood H. (2018). Young people and their engagement with healthrelated social media: New perspectives. Sport, Education, \& Society 24, 673-688. DOI: https://doi.org/10.1080/13573322.2017.1423464

[11] Quennerstedt M. (2013). PE on YouTube investigating participation in physical education practice. Physical Education and Sport Pedagogy 18 , 42-59. http://dx.doi.org/10.1080/17408989.2011.631000

[12] Harvey S., Pill S. (2018). Exploring physical education teachers 'everyday understandings' of physical literacy. Sport. Education \& Society 24, 841-854. https://doi.org/10.1080/13573322.2018.1491002

[13] Kitchin R. (2017). Big data - Hype or revolution? In L. Sloan, A. Quan-Haase (eds), The SAGE handbook of social media research methods (pp. 2739). Los Angeles: SAGE Publication Ltd.

[14] Campbell D., Gray S., Kelly J., Maclsaac S. (2018). Inclusive and exclusive masculinities in physical education: a Scottish case study. Sport, Education, \& Society 23, 216-228. DOI: https://doi.org/10.1080/13573322.2016.1167680

[15] Parker M. B., Curtner-Smith M. D. (2012). Sport education: A panacea for hegemonic masculinity in physical education or more of the same? Sport, Education, \& Society 17, 479-496. DOI: https://doi.org/10.1080/13573322.2011.608945

[16] White A., Hobson M. (2017). Teachers' stories: Physical education teachers' constructions and experiences of masculinity within secondary school physical education. Sport, Education, \& Society 22, 905-918. https://doi.org/10.1080/13573322.2015.1112779

[17] McEvilly N., Verheul M., Atencio M. (2015). Physical education at preschools: The meaning of 'physical education' to practitioners at three preschool settings in Scotland. Physical Education and Sport Pedagogy 20, 117-130. DOI: https://doi.org/10.1080/17408989.2013.798407

[18] Mikalsen H. K., Lagestad P. A. (2019). Adolescents' meaning-making experiences on physical education - in the transition from primary to secondary school. Sport, Education, \& Society 25, 802-814. DOI: https://doi.org/10.1080/13573322.2019.1662389

[19] Varea V., Gonzalez-Calvo G. (2020). Touchless classes and absent bodies: Teaching physical education in times of Covid-19. Sport. Education and Society 26, 1-15. DOI: https://doi.org/10.1080/13573322.2020.1791814 
[20] O'Brien W., Adamakis M., O'Brien N., Onofre M., Martins J., Dania A. et al. (2020). Implications for European physical education teacher education during the COVID-19 pandemic: A crossinstitutional SWOT analysis. European Journal of Teacher Education 43, 503-522. DOI: https://doi.org/10.1080/02619768.2020.1823963

[21] Berger P. L., Luckmann T. (1991). The social construction of reality: A treatise in the sociology of knowledge. London: Penguin Books. 